\title{
Sistem Pemberian Nutrisi Bayam Hidroponik Berbasis IoT Terintegrasi Telegram
}

\author{
Toto Supriyanto ${ }^{1}$, Tiasnita Andam Dewi ${ }^{2}$, Amalia Afa Zahra ${ }^{3}$, Asri Wulandari ${ }^{4}$ \\ 1,2,3,4Program Studi Telekomunikasi, Jurusan Teknik Elektro, Politeknik Negeri Jakarta, \\ Jalan Prof. Dr. G. A. Siwabessy, Kampus Baru UI Depok 16245, Indonesia \\ E-mail : toto.supriyanto@elektro.pnj.ac.id
}

\begin{abstract}
Abstrak
Hidroponik adalah metode budidaya tanaman tanpa menggunakan media tanah, tetapi memanfaatkan air/larutan mineral bernutrisi yang diperlukan oleh tanaman. Salah satu jenis tanaman hidroponik adalah bayam yang dapat tumbuh berkembang pada suhu $>25^{\circ} \mathrm{C}$ dan memerlukan nutrisi antara $410-900 \mathrm{ppm}$. Adakalanya pemilik tanaman tidak berada di area penanaman sehingga tidak sempat melakukan pemberian nutrisi tersebut. Sistem ini dibuat untuk monitoring kondisi air, suhu, nutrisi, mengaktifkan pompa air dan nutrisi, menyalakan lampu, dari jarak jauh melalui aplikasi bot telegram. Sistem terdiri dari Arduino Mega 2560, modul NodeMCU ESP8266 untuk pengiriman data ke aplikasi telegram melalui jaringan internet, sensor suhu DHT22 untuk mengetahui suhu lingkungan, sensor TDS untuk memantau konsenterasi nutrisi, sensor ultrasonic untuk ketinggian campuran air dan nutrisi, modul relay 4 channel untuk mengaktifkan tiga buah pompa, dan satu lampu. Pompa digunakan untuk menyiram nutrisi dan mengisi air. Lampu untuk menaikkan suhu, jika suhu $<25^{\circ} \mathrm{C}$. Hasil pengujian bot telegram, notifikasi diterima pengguna saat suhu disekitar tanaman $<25^{\circ} \mathrm{C}$, pemilik tanaman berhasil memberikan perintah menyalakan lampu melalui telegram. Saat ketinggian air nutrisi berkurang dibawah $8 \mathrm{~cm}$, dan konsentrasi nutrisi $<410 \mathrm{ppm}$, pemilik berhasil mengaktifkan pompa air dan pompa nutrisi. Saat konsenterasi nutrisi diatas 900 ppm, pemilik berhasil memberikan perintah pengurasan melalui telegram.
\end{abstract}

Kata Kunci: Arduino Mega, Hidroponik, NodeMCU, Sensor DHT22, Sensor TDS

\begin{abstract}
Hydroponics is a method of cultivating plants without using soil media, but utilizing water/nutrient mineral solutions needed by plants. One type of hydroponic plant is spinach which can grow at temperatures $>25^{\circ} \mathrm{C}$ and requires nutrients between 410-900 ppm. Sometimes the plant owner is not in the planting area so he does not have time to provide these nutrients. This system is made for monitoring water conditions, temperature, nutrients, activating water and nutrition pumps, turning on lights, remotely via the telegram bot application. The system consists of an Arduino Mega 2560, NodeMCU ESP8266 module for sending data to the telegram application via the internet, a DHT22 temperature sensor to determine the ambient temperature, a TDS sensor to monitor nutrient concentrations, an ultrasonic sensor for the height of a mixture of water and nutrients, a 4 channel relay module to activate three pumps, and one lamp. Pumps are used to flush nutrients and fill water. Lamp to raise the temperature, if the temperature is $<25^{\circ} \mathrm{C}$. The results of the telegram bot test, notifications are received by the user when the temperature around the plant is $<25^{\circ} \mathrm{C}$, the plant owner has succeeded in giving the order to turn on the lights via telegram. When the nutrient water level is reduced below $8 \mathrm{~cm}$, and the nutrient concentration is $<410$ ppm, the owner has successfully activated the water pump and nutrient pump. When the nutrient concentration was above 900 ppm, the owner managed to give a depletion order via telegram.
\end{abstract}

Keywords: Arduino Mega, DHT22 sensor, Hydroponics, NodeMCU, TDS sensor

\section{Pendahuluan}

Salah satu teknologi inovasi dalam budidaya tanaman yang cocok bagi pemilik rumah minimalis yaitu budidaya tanaman dengan teknik hidroponik. Tanaman bayam merupakan salah satu tanaman yang dapat di tanam dengan menggunakan metode hidroponik. Tanaman bayam mengandung banyak manfaat untuk kesehatan tubuh seperti dapat meningkatkan imunitas 
tubuh, kesehatan tulang, mencegah penyakit anemia, dan sebagainya. Tanaman bayam dapat hidup dengan suhu $\geq 25 \mathrm{C}^{\circ}$ dengan kadar konsenterasi nutrisi 410 ppm -900 ppm.

Namun masyarakat yang melakukan budidaya sering terjadi kegagalan di karenakan kurangnya pemantauan terhadap kondisi perkembangan tanaman bayam. Hal yang perlu diperhatikan adalah pasokan air, nutrisi, suhu air harus terjaga sesuai dengan tanaman. Jika kurangnya pemantauan pada tanaman dapat menyebabkan ketidaksempurnaan tanaman dalam berkembang, bahkan dapat menyebabkan tanaman mati. Dengan berkembangnya teknologi, untuk memantau kondisi perkembangan tanaman bayam dapat menggunakan sistem berbasis Internet of things (IoT) melalui aplikasi bot telegram. Aplikasi telegram akan memberikan notifikasi keadaan di area tanaman seperti suhu, dan ketinggian campuran air dan nutrisi. Selain itu telegram digunakan untuk mengendalikan jarak jauh untuk pengisian air, penambahan nutrisi, dan mengaktifkan lampu jika suhu dibawah dari yang sudah ditentukan, sehingga suhu tetap terjaga.

Pada sistem ini terdapat beberapa modul perangkat keras dan perangkat lunak yang terdiri dari:

\subsection{NodeMCU ESP8266}

NodeMCU adalah sebuah platform IoT yang bersifat open source, terdiri dari chip ESP8266 dimana didalamnya sudah termasuk processor, memori dan juga akses ke GPIO. Modul ini memiliki 8 pin digital, 1 pin input analog, 1 pin $\mathrm{Tx}, 1$ pin $\mathrm{Rx}, 1$ port micro USB, 1 tombol reset, dan sebuah antenna. NodeMCU dilengkapi dengan modul Wi-Fi ESP8266 yang dapat membuatnya terhubung ke jaringan Wi-Fi. Gambar 1 menunjukkan nodemcu esp8266 [1].

\subsection{Arduino Mega 2560}

Arduino Mega 2560 adalah sebuah board arduino yang menggunakan IC mikrokontroler ATmega 2560. Board ini memiliki pin I/O yang relatif banyak, 54 digital input/output,15 buah di antaranya dapat di gunakan sebagai output PWM, 16 buah analog input, 4 UART. Arduino Mega 2560 di lengkapi kristal 16 Mhz. Gambar 2 menunjukkan board arduino mega 2560 [2].

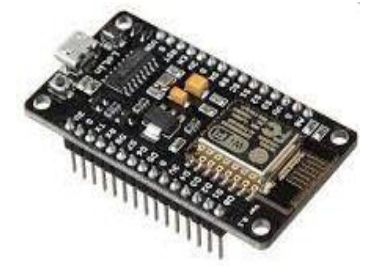

Gambar 1. NodeMCU ESP8266

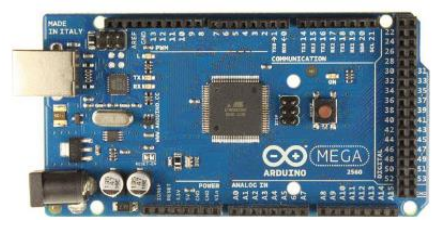

Gambar 2. Arduino Mega

\subsection{Sensor Ultrasonic}

Sensor ultrasonic HC-SR04 adalah sebuah sensor yang berfungsi untuk mengubah besaran fisis (bunyi) menjadi besaran listrik dan sebaliknya. Cara kerja sensor ini didasarkan pada prinsip dari pantulan suatu gelombang suara sehingga dapat dipakai untuk menafsirkan eksistensi (jarak) suatu benda dengan frekuensi tertentu. Sensor ultrasonic ini menggunakan gelombang ultrasonic (bunyi ultrasonic) [3]. Gambar 3 menunjukkan sensor ultrasonic.

\subsection{Sensor DHT 22}

Sensor DHT22 adalah sensor suhu dan kelembapan memiliki jangkauan pengukuran suhu dari $-40^{\circ} \mathrm{C}$ hingga $125^{\circ} \mathrm{C}$ dan tingkat kelembapan 0 sampai $100 \%$. Sensor DHT22 menggunakan komponen peraba kelembapan yang memiliki 2 elektroda dilengkapi substrat kelembapan diantara 2 elektroda. Ketika kelembapan dalam ruangan berubah, maka konduktivitas antara substrat berubah. Sedangkan untuk suhu diukur menggunakan negative temperature coefficient (NTC) atau thermistor. Gambar 4 memperlihatkan sensor suhu DHT22 [4].

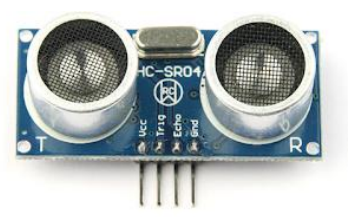

Gambar 3. NodeMCU ESP8266

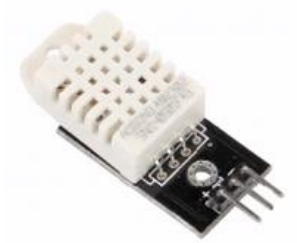

Gambar 4. Sensor suhu DHT22 


\subsection{Sensor TDS}

TDS adalah jumlah material yang terlarut di dalam air. Material ini dapat berupa karbonat, bikarbonat, klorida, sulfat, fosfat, nitrat, kalsium, magnesium, natrium, ionion organic, senyawa koloid dan lain-lain. Metode yang dapat digunakan untuk mengukur TDS dalam air adalah gravimetri dan konduktivitas listrik [5],[6]. Gambar 5 memperlihatkan sensor TDS.

\subsection{Modul Relay}

Modul relay adalah suatu komponen yang digunakan sebagai saklar penghubung/pemutus untuk arus beban yang cukup besar, dikontrol oleh sinyal listrik dengan arus yang kecil. Modul relay memerlukan arus sebesar 15-20 mA untuk mengontrol masing-masing channel, disertai dengan relay high current sehingga dapat menghubungkan perangkat dengan sumber tegangan AC $250 \mathrm{~V}$ 10A. Susunan kontak pada relay adalah normally open (NO) yang akan menutup bila dialiri arus listrik, dan normally close yang akan membuka bila dialiri arus listrik, Changeover adalah relay memiliki kontak tengah yang akan melepaskan diri dan membuat kontak lainnya berhubungan [3]. Gambar 6 . Menunjukkan modul relay.

\subsection{Arduino IDE}

Arduino integrated development environment (IDE) adalah sebuah aplikasi lintas platform (Microsoft Windows, Linux, MacOS) yang digunakan untuk menulis dan mengunggah program ke semua jenis board Arduino [7].

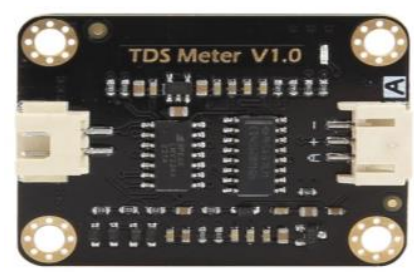

Gambar 5. Sensor TDS

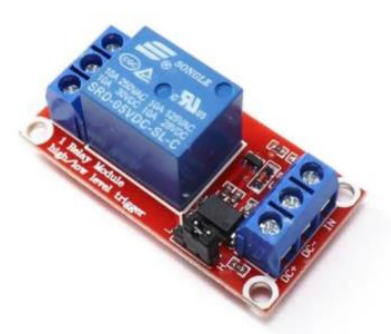

Gambar 6. Modul relay

\subsection{Telegram}

Telegram adalah aplikasi pesan instan berbasis cloud yang juga menyediakan layanan voice over internet protocol (VoIP). Telegram tersedia di Android, iOS, Microsoft Windows, macOS, dan Linux.

Telegram bot adalah sebuah application programming interface (API) berbasis hyper-text transfer protocol (HTTP) yang digunakan untuk membuat bot telegram pada aplikasi telegram [8]. Bot telegram dapat melakukan apa saja sesuai perintah yang sudah tersedia. Bot telegram bisa digunakan untuk melakukan pencarian, sebagai penghubung, pengingat, pengajar, pengintegrasi, dan lainnya. Untuk memprogram sebuah bot telegram di Arduino IDE, diperlukan sebuah library telegram bot. Ada berbagai jenis library telegram bot, yakni Ctbot, Universal Telegram Bot dan masih banyak lagi. Telegram Bot yang digunakan pada sistem adalah Ctbot.

\section{Metode Penelitian}

Alat ini menggunakan sensor TDS untuk mengukur konsentrasi campuran air dan nutrisi, sensor ultrasonic digunakan untuk mengukur ketinggian campuran air dan nutrisi yang sudah berkurang, dan sensor DHT22 digunakan untuk mengukur temperatur di sekitar tanaman. Data dari sensor-sensor tersebut akan diproses oleh Arduino Mega dan akan dikirimkan ke telegram melalui NodeMCU dengan bantuan Ctbot berupa data kondisi air, suhu, dan nutrisi.

Data dari sensor akan di terima oleh telegram sebagai notifikasi pemberitahuan. Notifikasi dari sensor suhu akan diberikan jika suhu $<25^{\circ} \mathrm{C}$ seperti "Suhu dibawah standar! Nyalakan lampu!”. Notifikasi dari sensor ultrasonic akan diberikan jika ketinggian suplai campuran air nutrisi kurang, seperti "Suplai air yang dicampur nutrisi kurang! Isi Air Nutrisi sekarang?”. Jika konsenterasi nutrisi $>900$ ppm terbaca oleh sensor TDS, akan memberikan notifikasi "Konsentrasi nutrisi melebihi batas ideal! Segera lakukan pengurasan!”. Notifikasi tersebut berguna agar pemilik tanaman segera mengetahui kondisi tanamannya dan mengirimkan perintah berupa pesan melalui telegram seperti untuk menambahkan air, menambahkan nutrisi, menguras tanki campuran air dan nutrisi atau menyalakan lampu. Diagram alir pembuatan koneksi antara NodeMCU dan telegram ditunjukan pada Gambar 7, dan flowchart sistem pemberian nutrisi bayam hidroponik diperlihatkan pada Gambar 8. 


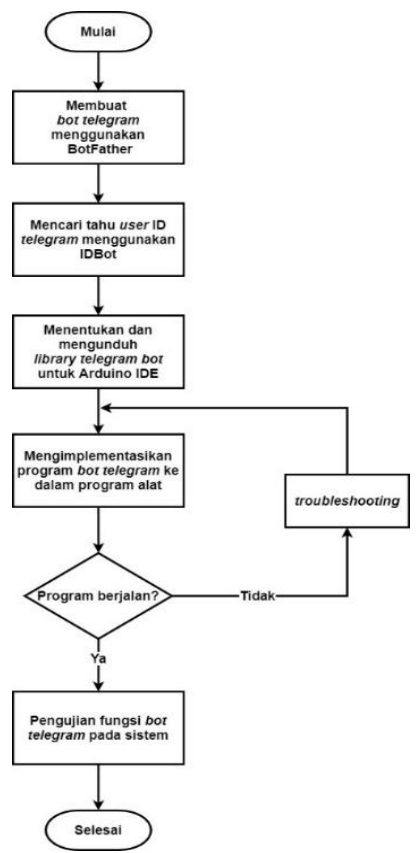

Gambar 7. Diagram alir pembuatan koneksi antara NodeMCU dan telegram

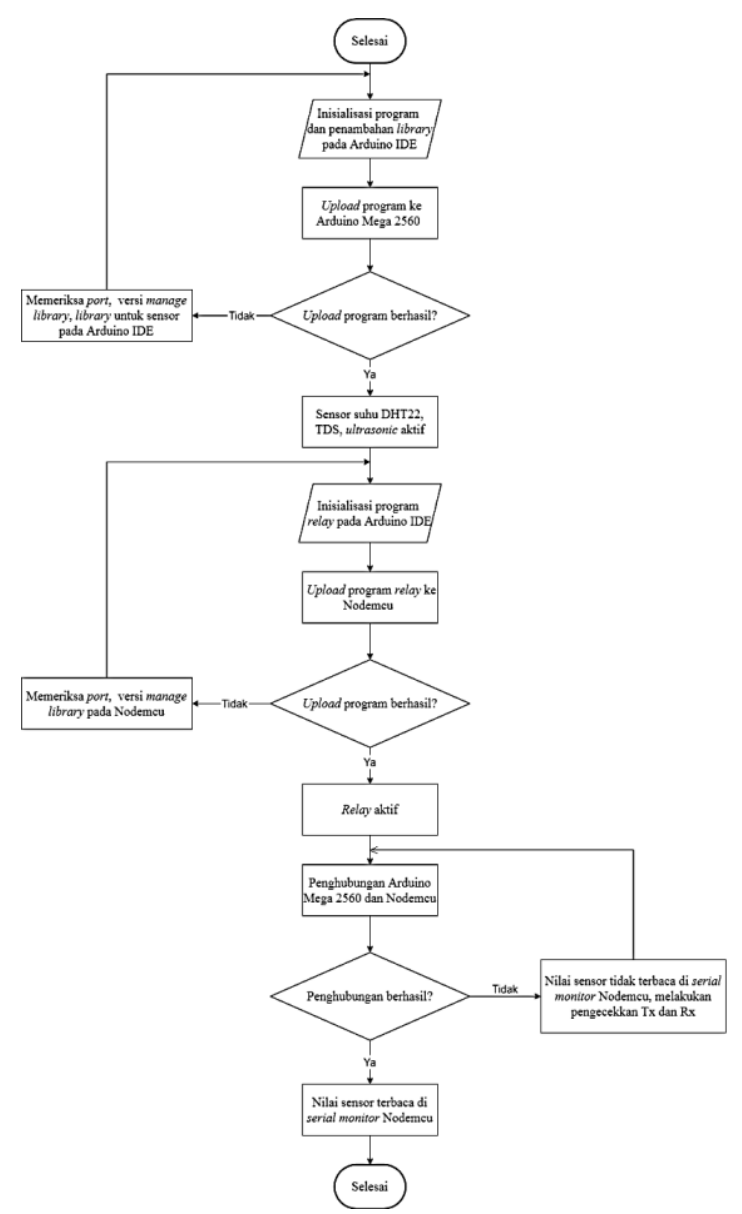

Gambar 8. Flowchart Sistem Pemberian Nutrisi Bayam Hidroponik

\section{Hasil dan Pembahasan}

Pengujian sensor TDS dilakukan pada air murni tanpa campuran nutrisi, nutrisi murni tanpa campuran air, dan campuran air dengan nutrisi. Sebagai perbandingan, nilai terbaik campuran air dan nutrisi pada bayam adalah sebesar 410 - 900 ppm. Didapat hasil pengujian pada air murni nilai output sensor sebesar 191,13 ppm, nutrisi murni output sensor 2629,46 ppm, dan campuran air dengan nutrisi output sensor $361,88 \mathrm{ppm}$. Pada saat nilai ppm dibawah rentang 410 - 900 ppm, maka pompa akan aktif mengisi air ataupun nutrisi smpai nilai sensor sesuai yang diijinkan.

Untuk pengujian sensor suhu DHT, pada saat pengukuran di air biasa output nilai sensor $29,10^{\circ} \mathrm{C}$. dan kondisi lampu mati. Pada saat pengukuran di air yang dicampur dengan es batu output nilai sensor $22,80^{\circ} \mathrm{C}$ dan lampu menyala. Suhu terbaik untuk tanaman bayam harus $\geq 25^{\circ} \mathrm{C}$. Oleh karena itu pada saat pengujian suhu $22,8^{\circ} \mathrm{C}$ lampu akan menyala agar menghangatkan kondisi lingkungan sekitar tanaman sehingga suhu akan naik diatas $25^{\circ} \mathrm{C}$ sesuai dengan yang diinginkan.

Pengujian sensor ultrasonic dilakukan untuk mengukur ketinggian berkurangnya campuran air dan nutrisi. Pengujian dilakukan dengan meletakkan sensor pada bagian atas penampungan air dan jarak ketinggian dibatasi maksimum dari dasar $8 \mathrm{~cm}$. Pada saat dilakukan pengujian sensor ultrasonic, ketika air campuran nutrisi mencapai ketinggian $8 \mathrm{~cm}$ dari dasar, pompa air akan aktif dan mengalirkan air atau nutrisi.

Untuk perbandingan pemberian campuran antara air dan nutrisi yang terbaik dilakukan pengujian seperti pada Tabel 1. Berdasarkan Tabel 1, perbandingan air dan nutrisi 2: 1 menghasilkan nilai sensor TDS sebesar $464 \mathrm{ppm}$. Nilai tersebut adalah yang terbaik karena berada pada rentang konsenterasi nutrisi tanaman bayam antara 410 - 900 ppm. Pada perbandingan yang lainnya antara air dan nutrisi nilai output sensor TDS diatas atau dibawah rentang yang diijinkan, sehingga tidak menghasilkan nilai yang baik.

Untuk pengujian aplikasi telegram dilakukan menggunakan bot telegram dengan nama bot "Sistem Pemberian Nutrisi Bayam Hidroponik". Pengujian dilakukan pada siang dan sore hari

Tabel 1. Perbandingan air dan nutrisi Perbandingan

\begin{tabular}{ccc} 
Air & Nutrisi & Output Sensor (ppm) \\
\hline 1 & 1 & $987.5 \mathrm{ppm}$ \\
1 & 2 & $1353 \mathrm{ppm}$ \\
2 & 1 & $464 \mathrm{ppm}$ \\
3 & 1 & $187.36 \mathrm{ppm}$ \\
\hline
\end{tabular}


Pada siang hari suhu air yang tercampur nutrisi adalah $34^{\circ} \mathrm{C}$ dan sensor TDS menunjukkan konsenterasi air yang tercampur nutrisi sebesar $587 \mathrm{ppm}$. Nilai suhu dan konsenterasi ppm tidak ada masalah masih dalam batas ambang yang diijinkan. Tampilan bot telegram diperlihatkan pada Gambar 9.

Pada sore hari suhu terbaca oleh sensor DHT $32^{\circ} \mathrm{C}$ dan sensor TDS bernilai $1044 \mathrm{ppm}$. Notifikasi yang dikirimkan oleh bot telegram tertulis "Suplai air yang tercampur nutrisi kurang! isi air nutrisi sekarang?". Hal ini menandakan tingginya campuran air dan nutrisi berkurang. Tampilan bot telegram diperlihatkan pada Gambar 10. Jika ketinggian air dibawah $8 \mathrm{~cm}$ maka melalui bot telegram dapat diberikan perintah mengaktifkan pompa untuk mengisi air. Tetapi jika ketinggian cukup, maka notifikasi akan diberikan "konsentrasi air nutrisi melebihi batas ideal! Segera lakukan pengurasan!". Hal ini menandakan bahwa konsenterasi air yang tercampur nutrisi melebihi batas standar, sehingga dapat diberikan perintah melalui bot telegram untuk menguras penampungan campuran air dan nutrisi.

Gambar 11 adalah contoh perintah dan notifikasi pada bot telegram. Tabel 2. menunjukkan notifikasi yang diterima pengguna saat mengetik atau menekan perintah yang telah tersedia pada "/Bantuan". Masingmasing perintah sudah berfungsi dengan baik, dan dapat menampilkan data hasil pengukuran yang dibaca oleh sensor DHT22, sensor TDS, dan sensor ultrasonic. Perintah yang berfungsi untuk mengontrol relay seperti "/IsiAirNutrisi", “/NyalakanLampu", "/MatikanPompa", dan "/MatikanLampu" dapat membuat kondisi relay 2 , relay 3 , dan relay 4 menjadi "LOW" yang berarti relay aktif dan "HIGH" untuk menonaktifkan relay.

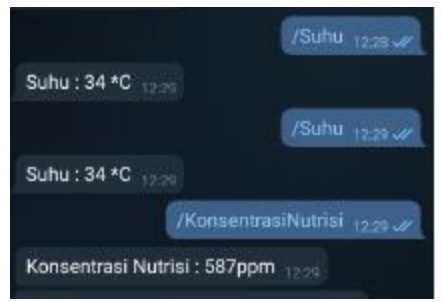

Gambar 9. Tampilan bot pengujian siang hari

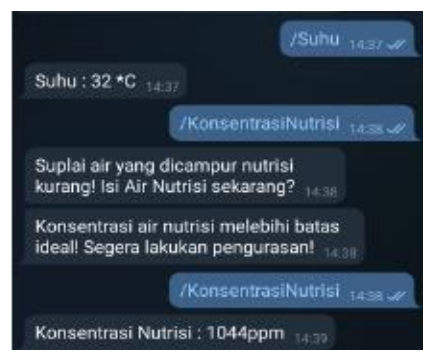

Gambar 10. Tampilan bot pengujian sore hari

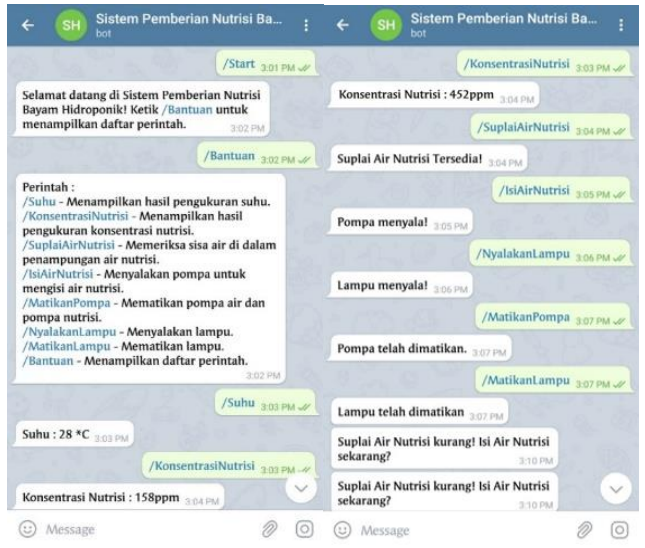

Gambar 11. Tampilan bot telegram untuk pemberian perintah dan notifikasi

Tabel 2. Daftar Perintah dan Notifikasi pada bot Telegram

\begin{tabular}{|c|c|c|}
\hline Perintah & Notifikasi & Keterangan \\
\hline /Suhu & Suhu : $28 * C$ & $\begin{array}{c}\text { Suhu disekitar } \\
\text { tanaman yaitu } \\
28^{\circ} \mathrm{C}\end{array}$ \\
\hline $\begin{array}{c}\text { /KonsentrasiNutr } \\
\text { isi }\end{array}$ & $\begin{array}{l}\text { Konsentrasi } \\
\text { Nutrisi : } \\
\text { 452ppm }\end{array}$ & $\begin{array}{c}\text { Konsentrasi air } \\
\text { yang telah } \\
\text { dicampur nutrisi } \\
\text { yaitu 452ppm }\end{array}$ \\
\hline /SuplaiAirNutrisi & $\begin{array}{l}\text { Suplai Air } \\
\text { Nutrisi } \\
\text { Tersedia! }\end{array}$ & $\begin{array}{c}\text { Suplai air yang } \\
\text { telah dicampur } \\
\text { nutrisi belum } \\
\text { berkurang }>7 \mathrm{~cm}\end{array}$ \\
\hline /IsiAirNutrisi & $\begin{array}{l}\text { Pompa } \\
\text { menyala! }\end{array}$ & $\begin{array}{l}\text { Pompa air (relay } \\
\text { 3) dan pompa } \\
\text { nutrisi (relay 2) } \\
\text { sudah dinyalakan }\end{array}$ \\
\hline /NyalakanLampu & $\begin{array}{l}\text { Lampu } \\
\text { menyala! }\end{array}$ & $\begin{array}{l}\text { Lampu (relay 4) } \\
\text { sudah dinyalakan }\end{array}$ \\
\hline /MatikanPompa & $\begin{array}{l}\text { Pompa telah } \\
\text { dimatikan. }\end{array}$ & $\begin{array}{l}\text { Pompa air (relay } \\
\text { 3) dan pompa } \\
\text { nutrisi (relay 2) } \\
\text { sudah dimatikan }\end{array}$ \\
\hline /MatikanLampu & $\begin{array}{c}\text { Lampu telah } \\
\text { dimatikan }\end{array}$ & $\begin{array}{l}\text { Lampu (relay 4) } \\
\text { sudah dimatikan }\end{array}$ \\
\hline
\end{tabular}

\section{Kesimpulan}

Sistem sudah dapat berfungsi sesuai dengan perancangan yang diinginkan. Pada saat suhu dibawah $25^{\circ} \mathrm{C}$, sistem akan memberikan notifikasi dan pemilik dapat memberikan perintah menyalakan lampu melalui telegram. Jika suhu sudah terpenuhi dapat memberikan perintah mematikan lampu. Begitu juga jika kadar 
campuran nutrisi dibawah 410ppm, system akan memberikan notifikasi ke telegram, dan pemilik dapat memberikan perintah melalui telegram untuk mengaktifkan pompa menambahkan nutrisi. Jika kadar nutrisi sudah cukup pemilik dapat memberikan perintah mematikan pompa. Sistem dapat juga mengirimkan notifikasi sesuai perintah yang diberikan melalui telegram, misalkan pemilik ingin memonitoring keadaan suhu, kadar nutrisi, ketinggian penampungan campuran air nutrisi. Jika sistem memberikan notifikasi kadar ppm tinggi, pemilik dapat melakukan perintah pengurasan penampungan nutrisi melalui telegram. Perbandingan percampuran nutrisi dan air yang terbaik adalah $1: 2$ dengan nilai konsenterasi 464 ppm, masih berada dalam batas rentang 410-900ppm untuk tanaman bayam.

\section{Daftar Acuan}

[1] L.K.P. Saputra, Y. Lukito, Implementation of air conditioning control system using REST protocol based on NodeMCU ESP8266. Int. Conf. Smart Cities, Autom. Intell. Comput. Syst. ICONSONICS 2017, vol. Januari, (2018) pp. 126-130.

[2] N. D. Setiawan, Otomasi Pencampur Nutrisi Hidroponik Sistem NTF (Nutrient Film Technique) Berbasis Arduino Mega 2560. Jurnal Teknik Informatika Unika St. Thomas (JTIUST) : Vol.3, No.0. 1 (2018).

[3] Y. Putra, Sistem Pemantauan dan Pengendalian Nutrisi, Suhu, dan Tinggi Air pada Pertanian Hidroponik Berbasis Website. Jurnal Coding, Sistem Komputer Untan : Vol.06, No.03 (2018).

[4] R. Gunawan, T. Andhika, Sandi, F. Hibatulloh, Sistem Monitoring Kelembapan Tanah, Suhu, pH dan Penyiraman Otomatis Pada Tanaman Tomat Berbasis Internet Of Things. Jurnal Telekontran, Vol. 7, No. 1 (2019).

[5] M. Rifai, dkk, Perancangan Sistem Nutrisi Otomatis pada Tanaman Hidroponik dengan Mikrokontroler NodeMCU Berbasis IoT. Jurnal Fidelitiy : Vol. 02, No. 1 (2020).

[6] Abdullah, Sistem Deteksi dan Monitoring Kondisi Kepekatan Larutan Nutrisi dan Suhu dalam Proses Cocok Tanam Hidroponik. Jurnal Ilmu Fisika dan Teknologi : Vol. 3, No. 1 (2019).

[7] A. Kadir, Panduan Praktis Mempelajari Aplikasi Mikrokontroler dan Pemograman Menggunakan Arduino, Yogyakarta: Penerbit Andi, 2013.

[8] C. Anggiat, Pembuatan Bot Telegram untuk Mengambil Informasi dan Jadwal Film Menggunakan PHP. Jurnal Infra. vol. 5 (2017). 